\title{
Agroindústria familiar: Experiência profissionalizante da Cooperativa da Agricultura Familiar Integrada (COOPAFI) em Francisco Beltrão - PR
}

\author{
Rose Mary Helena Quint Silochi ${ }^{1}$, Romilda de Souza Lima², Ivanira \\ Correia de Oliveira ${ }^{3}$
}

\begin{abstract}
RESUMO: Neste estudo são apresentadas ações desenvolvidas e resultados obtidos no período de 15 meses do projeto. O objetivo principal foi contribuir para a melhoria das tecnologias existentes e propor alternativas de controle de qualidade na pós-colheita de frutas e hortaliças em toda a cadeia, incluindo Boas Práticas Agrícolas (BPA), processamento de produtos alimentícios e comercialização, de modo a permitir o desenvolvimento e competitividade referente aos desafios de novos mercados.
\end{abstract}

Palavras chave: Agroindústria, gestão, tecnologia.

Áreas temáticas: Ruralidades e tecnologia.

\footnotetext{
1 Economista Doméstico. Ms. Ciência e Tecnologia Industrial. Docente da Universidade Estadual do Oeste do Paraná. Campus Francisco Beltrão, Unioeste. Doutoranda em Engenharia Agrícola UNIOESTE. Grupo de Pesquisa em Segurança Alimentar. rsilochi@yahoo.com.br

2 Economista Doméstica. Ms. Extensão Rural. Docente da Universidade Estadual do Oeste do Paraná. Campus Francisco Beltrão, Unioeste. Doutoranda em Extensão Rural - UFV. Grupo de Pesquisa em Segurança Alimentar - GEPSA e Grupo de Pesquisa em Desenvolvimento Rural. romis.lima@yahoo.com.br 3 Administradora. Ms. Engenharia de Produção. Docente da Universidade Estadual do Oeste do Paraná. Campus Francisco Beltrão, Unioeste. Grupo de Pesquisa em Grupo Multidisciplinar de Estudos Organizacionais. ivaniraoliveira@ymail.com
} 


\section{Family agribusiness: Professional experience of the Fami- ly Farming Cooperative Integrated in Francisco Beltrão - Paraná}

ABSTRACT: This study presents results and actions developed within 15 months of the project. The main objective was to contribute to the improvement of existing technologies and propose alternative control postharvest quality of fruits and vegetables throughout the chain, including Good Agricultural Practices (GAP), food processing and marketing, in order to allow development and competitiveness challenges relating to new markets.

Keywords: Agribusiness, management, technology.

Thematic area: Agricultural and technology.

\section{Agronegocios en la familia: Experiencia profesional de la Agricultura Familiar Cooperativa Integral en Francisco Beltrão - Paraná}

RESUMEN: Este estudio presenta los resultados y las acciones desarrolladas dentro de los 15 meses del proyecto. El objetivo principal es contribuir a la mejora de las tecnologías existentes y proponer alternativas de control de calidad post-cosecha de frutas y verduras en toda la cadena, incluyendo las Buenas Prácticas Agrícolas (BPA), procesamiento de alimentos y marketing, con el fin de permitir el desarrollo y la competitividad desafíos relacionados a nuevos mercados.

Palabras clave: Agroindustria, gestión, tecnología.

Áreas temáticas: Agricultura y tecnologia. 


\section{INTRODUÇÃO}

O sistema de cooperativismo surgiu da necessidade de viabilização de custos de insumos e conhecimentos de novas tecnologias de produção e comercialização. Foi com esse intuito que cooperativas de agricultura familiar, já existentes no Sudoeste do Paraná optaram por consolidar essa união, a qual resultou no Sistema de Cooperativas da Agricultura Familiar Integrada que, segundo Ferraz et al. (2008), teve início entre 2003 e 2004 . Atualmente esse sistema é formado por dezessete cooperativas, envolvendo aproximadamente 2.000 associados.

Em Francisco Beltrão, a Cooperativa de Agricultura Familiar Integrada (COOPAFI), anteriormente denominada Cooperativa de Profissionalização Artesanal da Agricultura Familiar (COPAAF), teve suas atividades iniciadas no ano de 2001, com o objetivo de atender os produtores rurais, associados que encontravam dificuldade em comercializar sua produção. Posteriormente, em 2008, foi inaugurado, sem o planejamento necessário, um centro de comercialização da Cooperativa.

De forma desestruturada e sem a organização esperada dos próprios cooperados, a cooperativa encontrou problemas de gestão, desde a produção primária, processamento dos produtos alimentícios até as etapas de comercialização, bem como dificuldades administrativas e financeiras que resultaram na limitação das atividades do referido espaço de comercialização.

Diante da situação, a direção da COOPAFI, juntamente com a União Nacional das Cooperativas da Agricultura Familiar (UNICAFES), teve a iniciativa de procurar a Universidade Estadual do Oeste do Paraná (UNIOESTE) para parceria em um projeto de extensão, com subsídios da Fundação Araucária, através da Secretaria de Estado da Ciência, Tecnológica e Ensino Superior (SETI) para contribuir com conhecimentos técnico-científicos e de inovação, no intuito de sanar suas deficiências nas áreas de gestão e controle de qualidade do local em questão e assim conseguir, inclusive, que o espaço se tornasse uma referência para o consumidor interessado em produtos orgânicos e de melhor qualidade.

Assim, em dezembro de 2008, forma-se uma equipe multidisciplinar, composta por docentes, acadêmicos e profissionais dos cursos de Administração e Economia Doméstica, para a condução do projeto intitulado "Desenvolvimento de Inovações Tecnológicas de Produtos Alimentícios e Agroecológicos da Pequena Agroindústria Familiar".

O projeto foi considerado pela Cooperativa como sendo de extrema importância socioeconômica, pois atuou junto a pequenos 
produtores e a COOPAFI, oportunizando conhecimento e possibilidade de implantação de novas tecnologias de produção, com ênfase na pós-colheita de frutas e hortaliças, processamento agroindustrial, gestão e comercialização, buscando assim a diversificação de renda.

Para tanto, o objetivo foi contribuir para a melhoria das tecnologias existentes e propor alternativas de novas tecnologias de pós-colheita, comercialização e processamento de produtos alimentícios, de modo a permitir o desenvolvimento e competitividade referente aos desafios de novos mercados. Buscou-se aprimorar técnicas já utilizadas, como também introduzir novas possibilidades de controle de qualidade na pós-colheita de frutas e hortaliças em toda a cadeia, incluindo Boas Práticas Agrícolas (BPA).

Assim, o objetivo do presente trabalho é analisar a experiência de intervenção, buscando mostrar limites operacionais e gerenciais das pequenas agroindústrias familiares, principalmente no processamento e comercialização de produtos alimentícios e, por outro lado, evidenciar contribuições para a sustentabilidade da agroindústria familiar, bem como identificar as contribuições para a sustentabilidade da agroindústria familiar.

\section{METODOLOGIA}

Os procedimentos metodológicos utilizados neste trabalho, bem como na realização das atividades do projeto, foram: i) Pesquisa bibliográfica, documental e observação para levantamento de informações da cooperativa e seus consumidores; ii) Investigação exploratória por meio da aplicação de questionários junto à Direção Administrativa da COOPAFI, consumidores que tinham por hábito utilizar do espaço de comercialização e associados, que são os próprios agricultores familiares; iii) Visitas em propriedades de associados para verificar as atividades agrícolas desenvolvidas e as da produção agroindústria artesanal, quando era o caso.

O projeto ora apresentado iniciou com pesquisa exploratória a respeito da cooperativa, seus cooperados e clientes. Os procedimentos de coleta basearam-se em entrevistas com dirigentes e demais cooperados e observações in loco. As entrevistas com dirigentes foram realizadas no início do projeto. As entrevistas com cooperados foram feitas nas propriedades após identificação dos mesmos, junto aos registros da cooperativa, elaboração de roteiro das visitas e agendamento. Nas propriedades houve também observação das atividades desenvolvidas. A pesquisa com clientes foi por meio de questionários, aplicados pelos bolsistas do projeto na cooperativa. 
Todo levantamento de dados ocorreu no período de dezembro de 2008 a abril de 2009.

Após esses procedimentos, os dados coletados foram sistematizados, utilizando-se da análise de conteúdo e estatística descritiva para, em seguida, dar inicio às ações de intervenção do projeto na proposição de alternativas de tecnologias de pós-colheita e processamento de produtos nas propriedades; gestão, comercialização e organização da área de vendas na cooperativa.

A população beneficiada pelo projeto foi de aproximadamente 150 pessoas, totalizando 30 famílias de associados da cooperativa de comercialização. Foram 18 agroindústrias e 12 produtores familiares.

\section{ABORDAGEM TEÓRICA}

As linhas de abordagem teórica utilizadas neste trabalho são aquelas que destacam aspectos relevantes sobre agricultura familiar na realidade na qual foi desenvolvido o projeto de extensão, como conceitos de agroindústria, o papel desta na agregação de valor para os produtos e a importância do cooperativismo como forma de buscar insumos e escoar a produção, procurando meios de tornar os produtos mais competitivos.

Também é destacada a função da informação nutricional dos produtos provenientes das agroindústrias familiares e da adoção das Boas Práticas de Manipulação e de Fabricação, BPM/F.

\section{Agricultura Familiar}

A agricultura familiar é caracterizada por haver laços de parentesco entre os proprietários ou responsáveis pela propriedade, constituindo uma forma de produção social possuindo basicamente três características, que são "o trabalho, a gestão e a propriedade", ambos ligados à família (PLEIN, 2003, p.46).

É argumentado por Neves (2003) que o Brasil tem quase $20 \%$ da área agricultável disponível no planeta, e o maior percentual de área cultivável em relação à área total dos países, com quase $70 \%$ do total do território nacional passível de exploração agrícola. A região do sudoeste do Paraná, de acordo com Lima (2003), possui em torno de $80 \%$ das propriedades rurais com menos de 50 hectares de área. Porém, devido ao relevo, o cultivo em algumas áreas de boa fertilidade é inviável, o que faz com que áreas que deveriam ser de preservação permanente passem a ser exploradas. Como a região é composta em sua maioria por pequenas e médias propriedades rurais, é utilizada a mão de obra familiar como força de produção. 
De acordo com Henn (2001), durante o processo de modernização pelo qual o campo brasileiro passou, a Agricultura Familiar caracterizou-se como um seguimento que resistia ao "moderno" sendo até mesmo tachada como atrasada, não conseguindo atingir os padrões de produtividade por não possuir a mesma tecnologia utilizada pela agricultura de grande escala. Mesmo com as dificuldades impostas, a agricultura familiar resistiu e foi em busca de alternativas para seu desenvolvimento. Surgiram então várias formas de organização, como o associativismo e o cooperativismo, que possuem suas bases na solidariedade, fortalecendo assim quem sobrevive da agricultura familiar.

A agricultura é definida como a arte de cultivar a terra. Arte essa decorrente da ação do homem sobre o processo produtivo à procura da satisfação de suas necessidades básicas. O processo produtivo, por sua vez, é o conjunto de eventos e ações através dos quais os fatores de produção se transformam em produtos vegetais e animais, conforme argumenta Santos (1996). A produção na pequena propriedade rural na atualidade tem os custos muito altos, o que dificulta a permanência das famílias no campo; muitas das que persistem procuram formas alternativas de complementar sua renda como implantar uma pequena agroindústria para beneficiar os seus produtos.

\section{Agroindústria}

Em meio a um processo de ampliação do desenvolvimento econômico-social, no qual vem passando o País, a agricultura familiar tem buscado encontrar seu espaço e também desenvolver-se. Diante de grandes multinacionais que, cada vez mais são tomadoras de preços, os pequenos agricultores buscam ferramentas para agregar sua renda familiar. E uma dessas ferramentas é a agroindústria familiar, que tem tido papel importante para o produtor rural, sobretudo, o de pequena escala de produção.

Segundo Oltramari (2005), compreende-se agroindústria como o beneficiamento e/ou transformação dos produtos provenientes de explorações agrícolas, pecuárias pesqueiras, extrativistas e florestais, abrangendo desde processos simples, como secagem, classificação, limpeza e embalagem, até processos mais complexos que incluem operações físicas, químicas ou biológicas como, a extração de óleos. Inclui também o artesanato em geral no meio rural.

As agroindústrias surgiram de uma constatação dos produtores rurais de que sua produção gerava excedente que acabava por ser descartado o que, consequentemente, significava em perda. Iniciou-se, assim, um processo de transformação das sobras da produção, tornando-a mais viável e lucrativa. Depois de transformados, 
os produtos são comercializados pelos próprios produtores, assim, diversificando renda e agregando valor a produção.

A implantação de pequenas agroindústrias familiares comandadas pelos próprios agricultores se constitui uma das alternativas econômicas para a permanência dos agricultores familiares no meio rural e para a construção de um novo modelo de desenvolvimento sustentável. Caracteriza-se como uma importante iniciativa para promover a participação dos agricultores familiares no processo produtivo, aumentando a inclusão social, promovendo a participação no desenvolvimento da cidadania, além de constituir uma alternativa para geração de trabalho, renda e uma melhoria nas condições de vida dos agricultores, sendo uma forma desenvolvimento regional (RADAELI, 2005).

Apesar de iniciativas governamentais para o fortalecimento da agricultura familiar, via políticas públicas, os pequenos agricultores têm dificuldades para usufruírem dos benefícios, principalmente no que diz respeito às agroindústrias familiares, às quais é aplicada basicamente a mesma legislação sanitária de grandes empreendimentos agroindustriais. Onde há uma demanda de recursos financeiros para adequação que vai além da capacidade das agroindústrias constituídas para processar o excedente da produção e gerar aumento de renda às famílias na pequena propriedade. $\mathrm{O}$ investimento necessário acaba por inviabilizar a atividade, devido à baixa escala de produção.

\section{Cooperativismo}

Nas últimas décadas, o cooperativismo vem ganhando força devido aos benefícios que proporciona aos pequenos produtores, no caso de cooperativas de comercialização, o suporte que oferece na parte da produção e venda dos produtos de seus associados.

De acordo com Rios (1987), o cooperativismo foi o fruto do movimento operário que resultou na criação de um modelo de associação com as características de propriedade cooperativa, a qual consiste numa associação de pessoas independente de contribuição financeira. Outra característica a ser considerada é a gestão cooperativa, que significa que o poder de decisão final é da assembléia dos associados, e por fim a repartição cooperativa, que indica a distribuição das sobras do capital depois de um ano de trabalho.

Crúzio (2005) define cooperativa como uma sociedade de pessoas que possuem objetivos comuns, associando-se à mesma por iniciativa e tendo dentro das condições exigidas livre ingresso. Com o pensamento de que "juntos somos mais fortes" é que os produto- 
res se motivam a criar cooperativas que possibilitem o alcance de melhores recursos na produção e novas formas de comercialização.

Segundo Martins (2006), as cooperativas podem ser classificadas em singulares, sendo necessárias no mínimo 20 pessoas físicas para constituí-las, e em cooperativas centrais que têm como associadas cooperativas singulares, sendo exigido no mínimo três para a sua existência.

As cooperativas utilizam um modelo de gestão o qual possibilita conseguir planejar, organizar, direcionar e avaliar as cooperativas. São sete os princípios básicos: adesão livre e voluntária, controle democrático pelos sócios, participação econômica dos sócios, autonomia e independência, educação, treinamento e informação, cooperação entre cooperativas, preocupação com a comunidade (OLIVEIRA, 2003).

As características específicas da empresa cooperativa determinam que ela possa ser concebida como parte integral ou extensão das empresas individuais de seus associados. A cooperativa é um meio pelo qual certas funções podem ser levadas a fio, mais efetiva e economicamente, quando realizadas por empresas associadas e não individualmente. A forma cooperativa de organização mantém a unidade entre propriedade e controle e especialmente, a unidade entre o uso e o controle da empresa. O associado participa na tomada de decisões e é considerado um fiscal na sua aplicação. No sistema cooperativo, constitui-se como princípio fundamental que o "excedente disponível” seja devolvido aos cooperados na proporção de sua participação nas operações comerciais. O excedente é distribuído aos associados na proporção do uso dos serviços da cooperativa (RIOS, 1987).

Essa forma de organização, se bem trabalhada, abre caminhos para os agricultores familiares, possibilitando-lhes intensificarem suas produções e investir em métodos que agreguem valor ao seu produto.

\section{Considerações sobre legislação, produção e comercialização de alimentos na agroindústria familiar}

O sistema cooperativo de comercialização de alimentos da agricultura familiar de pequeno porte, a que se refere o projeto, apresenta fragilidades desde o planejamento das atividades até mesmo quanto ao comprometimento do pequeno agricultor associado com relação à produtividade e a qualidade do seu produto ofertado ao consumidor no segmento varejista.

Neste sentido, buscou-se desenvolver junto aos associados, ações pontuais relacionadas à qualidade e segurança dos produtos 
tanto in natura, como processados baseados na legislação nacional com o objetivo de contribuir na comercialização de produtos regionais e assim agregar valor a agricultura familiar.

A política de qualidade na área de alimentos no Brasil está bem construída, pois define claramente a adoção de controle de qualidade, de garantia de qualidade (GQ) e de garantia da produção de alimentos seguros (APPCC/HACCP), através do controle dos pontos críticos (PCC/CCP) durante o processo de fabricação e distribuição de alimentos, de forma a prevenir a contaminação e garantir a segurança do alimento. Entretanto, a produção, o processamento e a comercialização de produtos alimentícios oriundos da agricultura familiar não cumprem com estas diretrizes.

O pequeno produtor não tem acesso a conhecimentos essenciais de garantia da qualidade de seus produtos, sejam eles in natura ou processados, desconhece inclusive a legislação, o que pode comprometer a comercialização junto a consumidores cada vez mais exigentes.

No Brasil, a legislação geral conta atualmente com duas Portarias e uma Resolução. A Portaria do Ministério da Saúde no ${ }^{0} 1428$, de 26 de novembro de 1993, precursora na regulamentação desse tema, dispõe, entre outras matérias, sobre as diretrizes gerais para o estabelecimento das Boas Práticas de Produção e Prestação de Serviços (BPF) na área de alimentos (BRASIL, 1993).

As BPF são manuais que definem as ações a serem adotadas no controle da qualidade dos alimentos, conforme o ramo de atividade abrange um conjunto de medidas que devem ser adotadas pelas agroindústrias, sejam elas de grande ou pequeno porte e tem por objetivo a segurança e a conformidade dos produtos alimentícios com os regulamentos técnicos. A legislação sanitária federal regulamenta essas medidas em caráter geral, aplicável a todo o tipo de indústria de alimentos e específico, voltadas às indústrias que processam determinadas categorias de alimentos (ANVISA, 2005).

Com a implantação desse manual, além de uma padronização dos alimentos, é assegurado ao consumidor um produto menos fraudulento. Sabe-se que, adotando as BPF, os alimentos serão monitorados desde os requisitos higiênico-sanitários dos edifícios, a manutenção e higienização das instalações, dos equipamentos e dos utensílios, o controle da água de abastecimento, o controle integrado de vetores e pragas urbanas, a capacitação profissional, o controle da higiene e saúde dos manipuladores, o manejo de resíduos e o controle e garantia de qualidade do alimento preparado.

Outro aspecto importante relacionado à qualidade de alimentos e a legislação nacional diz respeito à rotulagem dos produtos ali- 
mentícios embalados na ausência do consumidor que, a partir de 2001, passou a ser obrigatório no Brasil. Destaca-se a importância da rotulagem como uma das normas que mais tem contribuído para a discussão sobre o processamento seguro de alimentos e por consequência tem agregado valor aos produtos artesanais.

A rotulagem dos alimentos tem como objetivo dar orientação ao consumidor sobre a qualidade e a quantidade dos constituintes nutricionais dos alimentos, auxiliando em escolhas alimentares mais apropriadas e ainda, confiando à rotulagem um caráter de uma atividade de promoção à saúde.

Obter uma informação correta sobre os produtos alimentícios que o consumidor adquire agrega o direito à alimentação, pois contribui com práticas alimentares e estilos de vida saudáveis, por englobar a questão de segurança alimentar e nutricional (CAMARA, 2007).

\section{RESULTADOS E DISCUSSÃO}

Os resultados do projeto contribuíram para agregar conhecimento e possibilitar o uso de novas tecnologias de gestão, desde a pós-colheita, desconhecidas por parte dos produtores, até as etapas de comercialização. Essas tecnologias foram repassadas no sentido de facilitar as atividades agroindustriais, aumentar a competitividade de agricultores familiares, adequando-os às normas vigentes na área de alimentos. Além disso, contribuiu para ampliar os conhecimentos dos profissionais recém-formados e acadêmicos, participantes como bolsistas do projeto, sobre cooperativismo, agricultura familiar, comercialização, gestão administrativa, controle de qualidade e demais áreas, possibilitando formação profissional dos membros do projeto.

Inicialmente as atividades do projeto consistiram em diagnosticar o perfil e a preferência dos consumidores do Centro de Comercialização da COOPAFI, assim como conhecer e entender a forma de gestão administrativa da cooperativa e das agroindústrias familiares a ela associadas, oportunizando traçar metas e estratégias para alcançar os objetivos do projeto.

Em seguida realizou-se um estudo para melhor adequação do espaço físico, construindo Layout apropriado à comercialização de alimentos e produtos alimentícios da COOPAFI, de forma a aumentar sua vida de prateleira e ofertar ao consumidor produtos de qualidade sob os aspectos físicos, químicos e biológicos. Priorizou-se estudo sobre a importância da qualidade sensorial dos alimentos e produtos alimentícios. Neste sentido, foram também confeccionadas aproximadamente 100 informações nutricionais para produtos 
alimentícios provenientes da agroindústria artesanal que são distribuídos para comercialização na região sudoeste do Paraná.

As visitas de diagnóstico da realidade dos cooperados possibilitaram relatórios técnicos detalhados sobre as características socioeconômicas e tecnológicas das propriedades e agroindústrias familiares. A pesquisa abrangeu 18 agroindústrias familiares e 12 produtores rurais associados à cooperativa.

Segundo Ruiz et al. (2003), a agroindústria familiar se constitui a partir de motivações de natureza econômica e social, onde a principal motivação é de ordem econômica, via transformação artesanal dos excedentes da produção. Dentre as motivações sociais mais relevantes, destacam-se a fixação do produtor na propriedade rural e a manutenção da integridade familiar, via envolvimento de todos na produção, inclusive das mulheres da família.

Constatou-se que na COOPAFI e também em feiras de pequenos produtores são comercializados diversos tipos de produtos, como frutas e hortaliças, laticínios e derivados, panificação, embutidos, vinhos, compotas e geléias de frutas, congelados, artesanatos, entre outros. Os de panificação são produzidos em sua maioria pelas mulheres associadas à cooperativa, o que faz com que elas desempenhem um papel importante, pois os produtos de panificação têm alta demanda por serem oriundos da agricultura familiar.

No intuito de contribuir para a verticalização da comercialização, foram planejadas ações que viabilizaram a elaboração do Manual de Boas Práticas, a fim melhorar a qualidade higiênico-sanitária do espaço de comercialização dos produtos alimentícios e alimentos in natura.

Foi constatada baixa demanda de consumo pelos produtos comercializados pela COOPAFI. Em reuniões e visitas de incentivo à comercialização na cooperativa, realizadas durante as atividades do projeto, verificou-se que o associado não entende a COOPAFI como seu espaço de comercialização, e também o baixo nível cooperação entre os associados, surgindo muitas críticas, porém poucos demonstraram interesse em colaborar para melhorar as condições do centro de comercialização.

Como o centro de comercialização não possuía estratégias claras, elaborou-se um plano de marketing que aponta estratégias de ações a serem desenvolvidas no curto e médio prazo, as quais implementadas, irão melhorar a comercialização e, consequentemente a saúde financeira da cooperativa e seus associados. Segundo Las Casas (2006), os objetivos, metas e estratégias de marketing têm o intuito de conhecer o mercado, no qual a empresa está inserida, seu público-alvo, seus concorrentes e, principalmente conhecer o seu espaço, 
para em seguida traçar estratégias de ação de curto, médio e longo prazo. Além disso, algumas ferramentas de gestão foram utilizadas, como classificação $\mathrm{ABC}^{1}$ na comercialização de produtos, margem de contribuição, ponto de equilíbrio, previsão de vendas e de caixa.

Diante dos diagnósticos, sentiu-se a necessidade de capacitação para os associados, sendo ofertados treinamentos nas áreas de "Pós Colheita de Frutas e Hortaliças" e "Planejamento e Administração Rural”, também foi realizado uma feira no espaço físico da UNIOES$\mathrm{TE}$, objetivando divulgar os produtos oriundos da agricultura familiar e a marca da cooperativa.

Como forma de escoar a produção, a COOPAFI faz a intermediação entre agricultores e governo federal através do Programa de Aquisição de Alimentos (PAA) - Fome Zero. Nesse processo, o projeto de extensão teve participação efetiva no planejamento e elaboração de documentos necessários à inclusão dos pequenos agricultores no programa, mas devido a entraves na aquisição de alguns documentos, não foi possível o encaminhamento do projeto em tempo hábil. Contudo, as informações levantadas e a experiência tiveram fundamental importância na orientação dos gestores da cooperativa para o PAA seguinte e para elaboração do projeto de compra para a merenda escolar, que, segundo a lei federal $\mathrm{n}^{0} 11.947$, o município deve comprar no mínimo 30\% dos produtos da merenda escolar provenientes da agricultura familiar, incentivando assim o desenvolvimento local, a cultura regional e a colocação dos produtos do pequeno produtor.

Para o desenvolvimento das atividades relatadas anteriormente, foi necessário a capacitação dos bolsistas do projeto em planejamento, aplicação e construção de diagnóstico econômico-social, Rotulagem Geral e Nutricional de Alimentos, gestão, elaboração de relatórios de campo, confecção de Layouts para organização de espaço físico de comercialização, Controle de Qualidade e Produção Segura de Alimentos pelos métodos de Boas Práticas de Fabricação (BPF) e Boas Práticas Agrícolas (BPA).

Outra forma encontrada pela equipe em divulgar os trabalhos, o centro de comercialização e até mesmo incentivar e estimular o espírito de cooperativismo dos associados ocorreu através da realização de um evento como o Dia Mundial da Alimentação (16 de outubro de 2009), sob o tema "Alcançar a Segurança Alimentar em época de crise", com o intuito de incentivar o consumo de produtos oriundos da Agricultura Familiar Regional, motivando cooperados e também consumidores. Este evento foi divulgado nos meios de comunicação rádio e televisão do município de Francisco Beltrão e via on-line no youtube, mostrando que é possível alcançar o sucesso e melhorar a qualidade dos produtos e atendimento com esforço e dedicação. 


\section{CONSIDERAÇÒES FINAIS}

A Cooperativa e seus associados necessitam de apoio à sua sustentabilidade tecnológica e socioeconômica. Há necessidade de priorizar planejamento, ações, programas e projetos, com ênfase na qualidade dos produtos, orientação e capacitação dos produtores/processadores de alimentos, planos de atividades, traçados em toda a cadeia alimentar, desde a produção primária à comercialização, rotulagem dos produtos embalados, marketing e divulgação da marca COOPAFI, visando ampliar a visão de negócio na agricultura familiar artesanal. Outro aspecto relevante é o apoio à capacitação gerencial com o objetivo de solucionar problemas relacionados a questões econômico-financeiras, logística, custos e comercialização.

A participação das instituições de ensino superior em parceria com órgãos públicos é fundamental, pois possibilita a pesquisa aplicada, capacitação tecnológica para melhorar a qualidade de produtos, bem como oferecer assessoria e consultoria econômico-financeira. É importante, ainda, como espaço para a qualificação dos estudantes de graduação inseridos em projetos de extensão e pesquisa da instituição de ensino superior. É um espaço que lhes permite a troca de conhecimento e um relacionamento direto com os produtores associados à cooperativa e com seus dilemas na área produtiva, econômica e social.

\section{REFERÊNCIAS BIBLIOGRÁFICAS}

ARRUDA, G.A. Manual de Boas Práticas Volume I - Hotéis e Restaurantes, 2.ed. São Paulo: Editora Ponto Crítico, 1997.

ANVISA. Agência Nacional de Vigilância Sanitária. Portaria SVS/MS nº 326, de 30 de julho de 1997. Aprova e estabelece os requisitos gerais sobre as condições higiênico-sanitárias e de Boas Práticas de fabricação para estabelecimentos produtores/industrializadores de alimentos. Diário Oficial da União, 31 de julho de 1997. Disponível em: <www.anvisa.com.br/legis/portarias/326-97.htm>. Acesso em: 06 ago. 2005.

BRASIL, Ministério da Saúde. Secretaria de Vigilância Sanitária. Portaria ${ }^{\circ}$ 1.428 , de 26 de novembro de 1993. Regulamentos Técnicos sobre Inspeção Sanitária, Boas Práticas de Produção/Prestação de Serviços e Padrão de Identidade e Qualidade na Área de Alimentos.

CAMARA, M.C.L. Análise crítica da rotulagem de alimentos diet e light no Brasil. Rio de Janeiro: s.e, 2007.

CRÚZIO, H.O. Como organizar e administrar uma cooperativa: uma alternativa para o desemprego. 4.ed. Rio de Janeiro: Editora FGV, 2005.

FERRAZ, O.G.; BRANDÃO, S.; PASE, H.L. SOBER. XLVI Congresso da Sociedade Brasileira de Economia, Administração e Sociologia Rural, 2008. Disponível em: <http://www.sober.org.br/palestra/9/423.pdf >. Acesso em: 31 mar. 2010. 
HENN, I.A. et. al. (Orgs.). Programa dos agentes comunitários de desenvolvimento e crédito: proposta de articulação e formação na perspectiva da agricultura familiar. Francisco Beltrão: Infocos, 2001.

LAS CASAS, A.L. Marketing de serviços. 4.ed. São Paulo: Atlas, 2006.

LIMA, R.S. Análise reflexiva do histórico do desenvolvimento da agricultura no Paraná: em busca de uma sustentabilidade possível. In: Agronegócio e Desenvolvimento Sustentável. Francisco Beltrão: UNIOESTE - Campus de Francisco Beltrão, 2003.

MARTINS, S.P. Cooperativas de trabalho. 2.ed. São Paulo: Atlas, 2006.

NEVES, M.F.; CHADDAD, F.R.; LAZZARINI, S.G. Gestão de Negócios em Alimentos. São Paulo: Pioneira Thomson Learning, 2003.

OLIVEIRA, D.J.P.R. Manual de gestão das cooperativas: uma abordagem prática. 2.ed. São Paulo: Atlas, 2003.

OLTROMARI, S. O administrador e a gestão de agroindústrias: Desafios e oportunidades. In: Anais da III Semana de Administração e II Mostra Científica. Francisco Beltrão: UNIOESTE - Campus de Francisco Beltrão, 2005.

PLEIN, C.; SCHNEIDER, S. Agricultura familiar e Mercantilização. In: Agronegócio e desenvolvimento sustentável. Francisco Beltrão, 2003.

RADAELLI, A.B. Agroindústria e agricultura familiar. In: Anais da III Semana de Administração e II Mostra Científica. Francisco Beltrão: UNIOESTE - Campus de Francisco Beltrão, 2005.

RIOS, G.S.L. O que é cooperativismo. Editora Brasiliense: São Paulo, 1987.

RUIZ, M.S.; VENTURINI, V.; CAMBERLIN, W. et al. Agroindústria Familiar de Londrina-PR. Disponível em: <www.fisica.uel.br/SBPC_LD/agroind.htm>, em 04 de abril de 2010.

SANTOS, G.J.; MARION, J.C. Administração de Custos na Agropecuária. 2.ed. São Paulo: Atlas, 1996.

\section{VÍDEO:}

<http:// www.youtube.com/watch?v= oZnFGgMu17I\&fé ature = player_embedded $>$.

\section{NOTAS:}

1 Técnica de controle de estoque utilizada na gestão financeira para análise e avaliação de consumo de produtos, cuja finalidade é definir políticas de vendas. 